\title{
O status do processo de inclusão da pessoa com deficiência visual no sistema
}

\section{educacional: Uma revisão integrativa de literatura}

\author{
The status of the inclusion process of a person with visual impairment in the educational system: \\ An integrative literature review
}

Estado del proceso de inclusión de personas con discapacidad visual en el sistema educativo: Revisión integrativa de la literatura

\section{Resumo}

Os debates relacionados à educação inclusiva tiveram origem há poucas décadas, mas sofrendo forte influência de uma cultura segregacional que excluía pessoas (fenômeno construído historicamente por diversos preconceitos) por não pertencerem a um padrão comum. Sendo assim, é objetivo principal desta pesquisa investigar o status da inclusão da Pessoa com deficiência Visual - PDV no sistema educacional e são objetivos específicos: investigar as possíveis estratégias efetivas de ensino-aprendizagem; como se encontra a formação inicial e continuada dos professores e averiguar a percepção do aluno cego perante a realidade desse processo inclusivo. Para isto, foi feito um estudo qualitativo de cunho descritivo, através de palavras chaves escolhidas previamente e alguns critérios de inclusão e exclusão de modo a serem aplicados em bases de dados e periódicos renomados. Os resultados da pesquisa revelaram que é importante investir na formação inicial e continuada dos professores, de modo a sensibilizar e incentivar os mesmos para um trabalho reflexivo, de modo a reconhecer as peculiaridades do aluno cego e trabalhar de forma multiprofissional, já que o processo inclusivo não está longe de se efetivar. Também foi constatado que há diversas metodologias e estratégias na tentativa de incluir as PDV na escola. Tais manifestações são pressupostos básicos que torna o processo de ensino-aprendizagem mais acessível, porém ainda não inclusivo em sua totalidade. Sendo assim, há muito o que se fazer para que possamos considerar inclusivo o processo de ensino-aprendizagem da PDV.

Palavras-chave: Ensino; Deficiência visual; Educação inclusiva; Sistema educacional.

\begin{abstract}
The debates related to inclusive education originated a few decades ago, but suffering the strong influence of a segregational culture that excluded people (a phenomenon historically built by various prejudices) for not belonging to a common standard. Thus, the main objective of this research is to investigate the status of the inclusion of the Visually Impaired Person - VDP in the educational system and the specific objectives are: to investigate the possible effective teaching-learning strategies; how is the initial and continuing education of teachers and investigate the perception of the blind student to the reality of this inclusive process. For this, a qualitative study of descriptive nature was carried out, through previously chosen key words and some inclusion and exclusion criteria to be applied in databases and renowned periodicals. The results of the research revealed that it is important to invest in the initial and continuing education of teachers, in order to sensitize and encourage them to a reflective work in order to recognize the peculiarities of the blind student and to work in a multiprofessional way, since the inclusive process is not far from being effective. It was also found that there are several methodologies and strategies in the attempt to include the PDV at school. Such manifestations are basic assumptions that make the teaching-learning process more accessible, but not yet fully inclusive. Thus, there is much to be done before we can consider the PDV teaching-learning process inclusive.
\end{abstract}

Keywords: Teaching; Visual impairment; Inclusive education; Educational system. 


\begin{abstract}
Resumen
Los debates relacionados con la educación inclusiva se originaron hace unas décadas, pero sufriendo la fuerte influencia de una cultura segregacionista que excluía a las personas (un fenómeno históricamente construido por diversos prejuicios) por no pertenecer a un estándar común. Por lo tanto, el objetivo principal de esta investigación es investigar el estado de la inclusión de la Persona con Discapacidad Visual - PDV en el sistema educativo y los objetivos específicos son: investigar las posibles estrategias efectivas de enseñanza-aprendizaje; cómo es la formación inicial y continua de los profesores e investigar la percepción del alumno ciego a la realidad de este proceso inclusivo. Para ello, se realizó un estudio cualitativo de carácter descriptivo, a través de palabras clave previamente elegidas y de unos criterios de inclusión y exclusión a aplicar en bases de datos y publicaciones periódicas de reconocido prestigio. Los resultados de la investigación revelaron que es importante invertir en la formación inicial y continua de los profesores, para sensibilizarlos y estimularlos a un trabajo reflexivo, con el fin de reconocer las peculiaridades del alumno ciego y trabajar de forma multiprofesional, ya que el proceso inclusivo no está lejos de ser eficaz. También se encontró que hay varias metodologías y estrategias en el intento de incluir el PDV en la escuela. Tales manifestaciones son supuestos básicos que hacen más accesible el proceso de enseñanza-aprendizaje, pero aún no son totalmente inclusivos. Por lo tanto, hay mucho que hacer para que podamos considerar inclusivo el proceso de enseñanza-aprendizaje de los PDV.
\end{abstract}

Palabras clave: Enseñanza; Discapacidad visual; Educación inclusiva; Sistema educacional.

\title{
1. Introdução
}

Desde meados da década de 90 que no Brasil emergiram os debates envolvendo o novo modelo de atendimento escolar reconhecido como Inclusão Escolar. Esse viés emerge opostamente ao processo de integração e na prática tem gerado bastante discussão (Miranda, 2004).

A princípio, a educação especial foi vista e se estabeleceu por meio de uma cultura de segregação, desprezando assim crianças por não serem consideradas dentro de um padrão comum, como se não fosse possível educá-las e, por tanto, não se tornando possível que elas frequentassem as mesmas instituições de crianças sem deficiência. Nesse sentido, em vários países europeus, precisamente por volta da década de 70, o ponto de partida da educabilidade de todos, incluindo as pessoas com deficiências, apresentou dificuldades em tomar espaço (Plaisance, 2015).

E quando se trata da Pessoa com Deficiência Visual (PDV) na educação, as pesquisas apontam que está sendo excluída do universo escolar. Sem contar que essa exclusão é um fenômeno que foi construído historicamente por meio de diversos preconceitos, uma vez que a pessoa cega é tida ainda como incapaz não somente de enxergar, mas também em compreender a linguagem e até em raciocinar, tendo assim sua capacidade intelectual contestada e inferiorizada (Azevedo, 2013).

E, apesar do crescente investimento em estratégias e metodologias diferenciadas na educação, em especial na educação inclusiva, é nítido que temos muito que percorrer para o mais acessível e próximo das políticas de inclusão. Sem contar que há muito que conhecer sobre as deficiências, particularidades e individualidades de cada um, podendo assim diminuir ao máximo as práticas e atitudes excludentes.

É garantido pela Lei de $n^{\circ} 13.146$, de 6 de julho de 2015 sobre a inclusão da pessoa com deficiência que devemos considerar uma pessoa com deficiência aquela que tem algum tipo de impedimento a longo prazo e como exemplo as de natureza física, mental e visual, em interação com barreiras, resultando na obstrução da participação efetiva dessas pessoas na sociedade em termos de igualdade de condições com as demais pessoas que não tem alguma deficiência (Brasil, 2015).

Esta Lei de $\mathrm{n}^{\mathrm{o}}$ 13.146, de 6 de julho de 2015 define ainda que as PDV possuem o mesmo direito à igualdade de oportunidades que é fornecido às pessoas que não possuem alguma deficiência ou que não sofrem algum tipo de ação discriminatória. A lei preconiza ainda que se deve investir em formas de garantir o acesso igualitário em todos os ambientes e serviços da sociedade, incluindo as tecnologias assistivas, habilitação e reabilitação, materiais e equipamentos de apoio, sem contar nos serviços, métodos e técnicas, e recursos de modo a prestar assistência à PDV. 
É importante destacar que é dever do poder público fornecer tecnologias assistivas de modo a obter melhores condições ao processo de ensino-aprendizagem das pessoas com deficiências e isso inclui a adaptação dos livros fornecidos a pessoa cega, bem como fornecer a ampliação de caracteres, contraste e impressão em Braille (Brasil, 2015).

Tendo por base as Diretrizes Nacionais para a educação Especial na educação Básica, por exemplo, a inclusão impacta na adequação de um sistema de inclusão escolar por meio de metodologias, currículo, métodos avaliativos e atitudes advindas dos educadores (Brasil, 1994). Porém, não deixando de considerar que a formação de professores, assim como a postura desses profissionais implica em políticas públicas que emperram o processo de inclusão, já que essa formação é estruturada com base em conteúdos, técnicas e metodologias de ensino e, portanto, acabam engessando a prática docente, reduzindo-a a modelos e padrões que propõe incluir através de um atendimento especializado (Azevedo, 2013).

Tendo em vista que no Brasil a educação sempre apresentou vários problemas quanto ao seu progresso devido à falta de atenção a esta área, pela escassez de investimento em políticas públicas e na formação de professores; e na falta da busca por aprimoramento no currículo quanto ao processo de ensino pelos próprios docentes. Como se não bastassem esses fatores, não há um investimento no salário dos professores para que possam apresentar condições dignas de trabalho de modo a tornálos aptos a encarar com mais força e firmeza os desafios encontrados na educação (Diniz, 2017).

Porém, quando se trata da realidade educacional da PDV, além de todos esses fatores anteriormente citados, a imposição de barreiras torna essa realidade ainda pior, de modo a impossibilitar o progresso do ensino-aprendizagem. Sendo assim, a sociedade ainda possui um caráter excludente, preconceituoso e classificatório que, em conjunto, ao serem impostos às pessoas com deficiências, acabam atrapalhando no desenvolvimento da autonomia e aprendizagem individual delas (Diniz, 2017).

E isso se confirma quando observamos que a escola se diz inclusiva e, ao mesmo tempo, lida com as diferenças na realidade concreta com os alunos, acaba induzindo para dentro de sua práxis, estigmas da doença e perversão com esses alunos que não compõe o perfil tido como necessário a quem consome do produto educacional (Azevedo, 2013).

Sem contar que ainda não está longe de um ensino tradicional, que sempre foi pautado em quadro branco, exposição em data show e dependência dos livros didáticos e, apesar dos pequenos avanços no processo de inclusão, da inserção da tecnologia e de outras estratégias e ferramentas tecnológicas na educação sob a tentativa de tornar o aprender mais acessível, é necessário conhecer mais a fundo sobre as deficiências, direitos, deveres e o processo de inclusão, em especial quando trata da PDV (foco da vigente pesquisa) (Diniz, 2017).

Ainda há muito que ser explorado, seja por parte dos professores, seja pelos demais membros da escola, família e sociedade como um todo, uma vez que os direitos, atendimento e acesso à informação, o conhecimento e a igualdade de oportunidades são iguais a todos perante as leis (Diniz, 2017).

A pesquisa é voltada a discutir os aspectos da acessibilidade e de inclusão voltada para as pessoas com cegueira total. Partindo dessa premissa, é objetivo principal desta pesquisa investigar o status da inclusão da PDV no sistema educacional e são objetivos específicos: investigar se há estratégias efetivas de ensino-aprendizagem em prol dessa inclusão; como se encontra a formação inicial e continuada dos professores quanto ao tema e averiguar a percepção do aluno cego perante a realidade desse processo inclusivo.

\section{Metodologia}

Trata-se de uma pesquisa bibliográfica, uma vez que o estudo foi realizado de forma sistemática, na busca de informações recentes e relevantes sobre o assunto, com base em materiais publicados em periódicos acessíveis ao público em geral. Sobre a pesquisa bibliográfica, Moresi (2003, p.35-36) pondera que: 
Pesquisa Bibliográfica é aquela baseada na análise da literatura já publicada em forma de livros, revistas, publicações avulsas, imprensa escrita e até eletronicamente, disponibilizada na Internet. A revisão de literatura/pesquisa bibliográfica contribuirá para: - obter informações sobre a situação atual do tema ou problema pesquisado; - conhecer publicações existentes sobre o tema e os aspectos que já foram abordados; - verificar as opiniões similares e diferentes a respeito do tema ou de aspectos relacionados ao tema ou ao problema de pesquisa (Moresi, 2003, p.35-36).

Essa pesquisa também é qualitativo-descritiva, uma vez que se baseia na percepção e no entendimento das pessoas, assim, trabalha para compreender a singularidade de cada indivíduo a ser pesquisado e os resultados são frutos da interação entre quem pesquisa e quem é pesquisado (Stake, 2011). Godoy, em relação aos processos da pesquisa qualitativa, pondera que:

Os estudos denominados qualitativos têm como preocupação fundamental o estudo e a análise do mundo empírico em seu ambiente natural. Nessa abordagem valoriza-se o contato direto e prolongado do pesquisador com o ambiente e a situação que está sendo estudada. Visando à compreensão ampla do fenômeno que está sendo estudado, considera que todos os dados da realidade são importantes e devem ser examinados. O ambiente e as pessoas nele inseridas devem ser olhados holisticamente: não são reduzidos a variáveis, mas observados como um todo (Godoy, 1995, p. 62).

Esse tipo de pesquisa busca encontrar significados das experiências pessoais, tendo em vista que elas transformam outras pessoas. Os pesquisadores são os instrumentos da pesquisa ao observar as ações e os contextos e a pesquisa qualitativa é composta pelas interpretações dos pesquisadores, das pessoas estudadas e dos leitores dos relatórios (Stake, 2016).

Os critérios de inclusão são: artigos e demais trabalhos publicados nos últimos 5 anos; trabalhos em português, inglês e espanhol; trabalhos acadêmicos com experiências validadas no Brasil, tendo em vista que a pesquisa está direcionada a este país e artigos com textos completos. E outras duas estratégias foram a análise textual prévia dos resumos dos trabalhos, bem como uma busca nas referências dos artigos e trabalhos científicos.

Critérios de exclusão: foram excluídos trabalhos com escassez de informações quanto ao tema em questão; trabalhos sem disponibilidade do texto integral; trabalhos publicados nos anos que antecedem o tempo delimitado nesta pesquisa e trabalhos de origem não identificada.

Dentre os bancos de dados, que incluem os periódicos, que foram selecionados, estão o portal de Periódicos CAPES (Coordenação de Aperfeiçoamento de Pessoal de Nível Superior), Scielo (Livraria científica e eletrônica online) e google acadêmico, tendo em vista sua enorme abrangência de pesquisa para encontrar os trabalhos acadêmicos (monografias, dissertações e teses) e artigos científicos, assim como foram consultados os repositórios de instituições de ensino (IE’s) quanto às informações referentes aos trabalhos acadêmicos.

Primeiramente, foi executada uma busca nos filtros de pesquisa dos bancos de dados, com o foco em artigos estritamente relacionados ao tema da pesquisa. Foram utilizadas ao máximo possível as ferramentas de filtragem para a coleta dos trabalhos acadêmicos no google acadêmico e nos repositórios. Quanto aos termos e/ou palavras descritoras utilizadas para a busca desses trabalhos científicos foram: "deficiência visual” e "inclusão da pessoa com deficiência visual”.

\section{Resultados e Discussão}

\subsection{A deficiência visual e algumas barreiras que impossibilitam o desenvolvimento da pessoa com deficiência visual na} educação

Nem mesmo a Organização Mundial da Saúde (OMS) consegue uma definição ideal para a deficiência em si. Definir deficiência é quase que impossível. E é intangível saber onde começam os limites de uma pessoa, bem como até onde chegam seus alcances. A OMS conseguiu levar as pessoas a terem mais ou menos a possibilidade de Inclusão social ao criar a 
Classificação Internacional de Funcionalidade, Incapacidade e Saúde que não consegue definir todos os tipos de deficiência (Ribas, 2017).

É considerada pessoa com deficiência visual, uma pessoa com baixa visão ou cegueira. Baixa visão ou visão subnormal é quando o valor da acuidade visual corrigida no melhor olho é menor que 0,3 e mais elevado ou igual a 0,05 ou seu campo visual é menor que $20^{\circ}$ no melhor olho com a melhor correção óptica. É considerado cegueira quando esses valores são encontrados abaixo de 0,03 ou quando o campo visual for menor do que $10^{\circ}$ (Brasil, 2008).

Na educação inclusiva para a PDV foi encontrada diversas barreiras que impossibilitam os alunos em aprender e se desenvolver assim como os demais estudantes sem deficiências. Algumas dessas barreiras são denominadas de urbanísticas, arquitetônicas, as que estão presentes nos transportes, nas comunicações, as chamadas barreiras atitudinais e tecnológicas (Brasil, 2015).

Como exemplo, as barreiras urbanísticas estão presentes nas vias e em espaços públicos e privados que estão dispostos a uso público ou coletivo. As arquitetônicas estão na estrutura da arquitetura de edifícios públicos e privados. As barreiras nos transportes estão presentes nos diversos meios de locomoção dos alunos, já as barreiras atitudinais são aquelas encontradas em comportamentos e atitudes que dificultam e/ou impossibilitam as PDV em participar em termos de condições e igualdade de direito com as demais pessoas sem deficiências. As barreiras tecnológicas são as que impedem o acesso das PDV tanto à tecnologia quanto às diversas áreas do conhecimento (Brasil, 2015).

\subsection{O processo de inclusão da pessoa com deficiência visual no sistema educacional}

Numa pesquisa de campo realizada por Selau, Damiani e Costas (2017) notou-se que para se superar as barreiras e promover a inclusão de alunos cegos em Universidades, é necessário primeiramente buscar subsídios em prol de uma definição sobre políticas de acessibilidade para além de se ancorar ao Ministério da Educação (MEC), onde cada Universidade deve desenvolver suas próprias políticas institucionais sobre educação inclusiva, repletas de objetivos e caracteres próprios, de modo a promover a articulação à comunidade acadêmica, podendo de fato firmar um compromisso com base na proposta de inclusão.

A inclusão do aluno cego, assim considerada pelos estudantes cegos da pesquisa de Selau et al. (2017) é um marco que depende também desses próprios sujeitos e dito por eles, eles próprios também devem ter iniciativa em querer estudar numa Universidade, através do aperfeiçoamento da comunicação com os demais colegas, através de cobranças de uma estrutura arquitetônica adequada e/ou mais acessível para o desenvolvimento da educação superior e buscar estudar sozinho ou em grupos, mas que incluam em seus cronogramas, horários, além dos realizados dentro das instituições de ensino superior.

Essas ações dos estudantes são necessárias, mesmo que esses direitos já sejam previstos na política nacional de educação especial que propõe que no ensino superior o foco esteja na criação de Núcleos de Acessibilidade, com investimento abundante em tecnologia para o acesso ao conhecimento e à informação (Bruno \& Nascimento, 2019).

O fato de os próprios alunos cegos buscarem a promoção da inclusão dos mesmos no sistema educacional não quer dizer que essa seja a única forma de se buscar a inclusão educacional, mas foi algo destacado pelos 8 alunos cegos entrevistados. Além disso, os professores possuem um papel muito importante na busca por estratégias de inclusão da PDV, através da facilitação do aprendizado (Selau et al., 2017).

Com relação às pesquisas que são feitas com base na percepção de alunos cegos no sistema educacional, como é o caso do estudo de Lima (2019), ao serem indagados sobre as dificuldades na disciplina de química, um aluno respondeu que tanto o professor quanto os demais alunos não colaboram e que o professor o libera da exigência de execução da tarefa quando não consegue realizar a atividade. Outro aluno afirma que o professor não consegue fornecer o auxílio necessário para que facilite a aprendizagem e outro aluno afirma que nas aulas não consegue aprender os assuntos propostos porque defende que o professor não consegue auxiliar e que não há materiais da referida área o suficiente para ajudá-los (Lima, 2019). 
O investimento em políticas públicas educacionais para a inclusão das PDV é um dos passos a serem dados em prol da educação cada vez mais inclusiva desses educandos e isso implica no investimento da formação continuada dos professores (Fortes \& Martins, 2017).

A pesquisa de Fortes e Martins (2017) destaca através das respostas coletadas dos docentes participantes, antes e após o desenvolvimento de um curso de formação continuada, uma reconstrução dos conhecimentos dos professores, segundo os autores:

[...] houve uma reconstrução, embora ainda pequena, dos seus saberes. Tal fato nos faz refletir sobre o papel da formação continuada frente ao contexto da inclusão, que precisa ultrapassar o muro de cursos pontuais, pois, mesmo sendo importante com vistas a proporcionar pequenas ou grandes mudanças na percepção e na prática docente frente aos educandos com deficiência visual, precisa se configurar de maneira mais presente na cultura na instituição de ensino, como algo instituído e formalizado no calendário acadêmico, nas reuniões pedagógicas empreendidas (Fortes \& Martins, 2017, p.50).

$\mathrm{Na}$ parte pedagógica, o professor deve estar em constante comunicação com o educador responsável pela sala de recursos multifuncionais para elaborar seus planos de aula e, podendo assim, reconhecer os potenciais dos alunos com deficiência e ter acesso às estratégias de ensino que leve em consideração os diversos estilos de aprendizagem das PDV. É importante a interação e debate entre os professores, possibilitando a troca mútua de conhecimento, pois, D. S. D. R. Pereira, Tavares e Silva (2021) em sua pesquisa enfatizam que a falta de comunicação é uma das principais questões que dificultam o trabalho dos professores da área da educação especial e, por tanto, aqueles do Atendimento Educacional Especializado (AEE) na Sala de Recursos Multifuncionais (SRM).

Com essa interação profissional, os alunos cegos aprenderão com mais facilidade, sem contar que assim sendo, estes podem acompanhar de forma mais proveitosa e ativa e, com isso, poder desenvolver as competências e habilidades, resultando no alcance dos objetivos propostos pelos componentes curriculares.

Outros fatores que devem ser levados em consideração pelos professores no desenvolvimento de atividades pedagógicas para os cegos são: Adaptar, construir, e reconstruir os conhecimentos de acordo com as vivências dos alunos; Reconhecer que os alunos cegos percebem o mundo e interpreta o ambiente ao seu redor de forma diferente, através dos sentidos remanescentes que geralmente são aguçados (Lima, 2019).

Ainda, segundo Lima (2019, p.11): "É nesse sentido que a adaptação metodológica deve ser construída, buscando reconhecer as especificidades e detalhes a partir do uso de tamanhos, texturas, relevos diferentes de fáceis percepções táteis".

Os alunos entrevistados na pesquisa de Lima (2019) revelaram que sentem a necessidade dos professores trabalharem mais com materiais táteis, pois só as teorias não vos ajudam a compreender os conteúdos de forma adequada, já com esse tipo de modelo, é possível "ver" a forma das estruturas. Sendo assim, é possível entender que os modelos táteis quando bem empregados no ensino das diversas disciplinas escolares, possibilitam a formação de modelos mentais das estruturas estudadas, através dos diversos relevos e texturas empregadas em sua construção.

Numa pesquisa realizada por Lavorato e Mól (2016) foi analisado que metade dos alunos cegos deste estudo acredita que o piso podotátil (um elemento que contribui para a orientação espacial do aluno cego) é uma estrutura que torna o ambiente escolar mais acessível e eficaz. Ainda segundo esse estudo, a Associação Brasileira de Normas Técnicas - ABNT criou parâmetros que devem ser seguidos para a colocação de tais pisos, já que é através dele que a PDV se locomove com autonomia e independência.

Os alunos cegos da pesquisa de Lavorato e Mól (2016) ainda contribuem que não se sentem incluídos em sua maioria. Há relatos de alunos que de fato se sentem excluídos não somente na disciplina, mas também pela escola de modo geral, que 
não é realizada nenhuma adaptação dos gráficos, e quanto aos alunos cegos que se sentem incluídos, não conseguem dizer o porquê se sentirem "inclusos".

Ainda nessa pesquisa os alunos destacam que sentem a necessidade de que os professores tratem todo mundo por igual e que tenha um curso que ensinasse a trabalhar e ensinar a eles. Tal narrativa representa um vazio na relação professoraluno, o que soa como um pedido de ajuda cheio de significados (Lavorato \& Mól, 2016).

Partindo desses resultados, observa-se que as escolas não estão sendo inclusivas, os professores não possuem a formação necessária e há claramente uma exclusão de alunos cegos, apesar das alternativas que tornam o ambiente um pouco acessível.

Quanto à questão dos professores, nos resultados da pesquisa de Urzedo, Jorge e Portela (2020), constatou-se que apesar da implementação de diversas políticas de inclusão das pessoas com deficiência no Brasil a partir da década de 90, percebe-se que a maioria dos professores desconhecem as dificuldades e barreiras, e também não possuem uma capacitação adequada para trabalhar de forma inclusiva, principalmente com as PDV Os educadores necessitam de uma formação técnica e quanto à inserção de informações sobre as demandas das PDV bem como da viabilidade das metodologias e materiais de ensino já existentes para beneficiar essas pessoas.

Nesse viés, é importante ressaltar que apesar do docente não estar preparado para receber um aluno com deficiência visual na escola, é dever do professor, como um profissional da educação, buscar metodologias inclusivas para promoção da aprendizagem desse aluno (Urzedo et al., 2020). Dessa forma, o professor deve procurar cursos e formações para construir e reconstruir seus conhecimentos, podendo ser até mesmo por meio de aprendizagem autodidata.

É importante incluir atividades que promovam uma reflexão sobre as particularidades de cada indivíduo para mostrar que as pessoas apresentam suas singularidades, através de dinâmicas como: futebol no escuro, "não vale usar a mão", de andar numa cadeira de rodas, aprender um pouco de libras e etc., de modo a promover a construção de saberes, desenvolver atitudes e tomadas de decisões mútuas e também o respeito a pessoas com necessidades especiais, como sugere Marcos Lima, jornalista e maior YouTuber cego do Brasil (Impulsiona, 2020).

É importante destacar que também é objetivo dessas atividades, o desenvolvimento da empatia e socialização, fazendo com que a comunidade escolar se prontifique e assim, permita que os alunos sem deficiência reconheçam que a deficiência faz parte da humanidade, podendo assim promover o reconhecimento das potencialidades dos colegas com deficiência sem descriminação (Impulsiona, 2020).

Acredita-se que desse modo, como tais estratégias tornam o processo de ensino-aprendizagem mais acessível para as PDV elas podem promover uma educação inclusiva para além das premissas apontadas em lei e decretos da área da educação inclusiva e assim, através da prática, poder tornar os espaços escolares mais inclusivos.

Sem contar que, é importante a solidariedade dos alunos e professores, a execução de trabalhos diversos em grupos para o compartilhamento e amplificação e construção dos conhecimentos, erradicando com o modelo tradicional de ensino que exclui alunos com deficiência na participação das atividades escolares de forma a promover o isolamento dos mesmos.

E, um exemplo de como se tornar as aulas mais inclusivas para as PDV é destacado no trabalho de Robalinho e Costa (2019) no qual trabalharam na construção de um jogo digital junto com alunos cegos no Ensino Médio de uma escola de referência na cidade do Rio de Janeiro, contendo elementos auditivos, imagéticos e funcionais, com a utilização de elementos lúdicos, possibilitando a inclusão dos estudantes com deficiência visual, o jogo chamado de "trilha do conhecimento" foi construído no Sistema Dosvox e, integrado a ele, o programa Jogavox.

Segundo Nery e Sá (2018), com a ludicidade o professor instiga o prazer em aprender, a participação de todos os alunos cegos e sem deficiência no ensino regular de forma mais inclusiva, o que torna possível novas formas de aprender. E, para que isso aconteça é necessária uma reformulação nos planos de ensino dos professores, de modo a inserir tais estratégias 
lúdicas. Nery e Sá (2018) concluíram que é possível trabalhar com estratégias lúdicas em busca de acessibilidade e inclusão na disciplina de matemática, como os jogos digitais, mosaico geométrico, tangram (quebra-cabeça bidimensional, em cinco formas diferentes), cubo soma, torre de Hanói, cubo mágico, dentre outros.

Além disso, a relação professor-aluno é primordial para que haja uma inclusão e isso também se justifica devido ao fato de que quando o professor os deixa passarem por despercebidos ou atribuem nota sem merecimento, sem exigir o mesmo que se exige dos demais sem deficiência visual, acaba atrapalhando, impondo barreiras e contribuindo para a falsa ideia de inclusão (Selau et al., 2017).

Para tornar o ambiente educacional mais inclusivo é necessário que os professores estejam abertos a causa da educação inclusiva propriamente dita e para isso, buscar cursos de formação continuada, acaba por facilitar nesse processo, sendo possível desenvolver mais o lado empático, que é muito necessário, que se sensibilizem e busquem novos conhecimentos, conforme as necessidades específicas de seus alunos (Fortes \& Martins, 2017; Medeiros, 2020).

Primeiramente, é preciso que o professor conheça as limitações enfrentadas pelos alunos cegos. A partir daí, irá trabalhar através de uma reflexão para que haja grandes transformações em sua prática pedagógica. Através da formação continuada, o professor trabalha lado reflexivo e, assim sendo, ressignifica a compreensão que possui sobre o aluno cego e sua educação. Tendo como base essas afirmações, é preciso um investimento maior na formação dos professores quanto à questão de conhecimento dos alunos com deficiência visual, de modo a estimular a sensibilização desses profissionais (Medeiros, 2020).

Sendo assim, deve haver uma preparação pedagógica dos professores para o atendimento de todos os alunos, podendo dialogar com o aluno cego sobre a relação professor-conteúdo-alunos, aumentar a escala de tempo de entrega de atividades, mediar à relação entre o aluno cego com os demais, elaborar formas avaliativas de acordo com as possibilidades do aluno cego e incentivá-los a concluírem o ensino superior (Selau et al., 2017).

Marchi e Silva (2016) analisaram a oferta do curso de Mecdaisy, que é uma tecnologia brasileira que traz sintetizador de voz por parte dos professores de química para alunos cegos. A implementação de um curso novo como este, fez com que houvesse uma reflexão que propicie saberes a prática docente, bem como uma compreensão de que existem alternativas que fazem diferença, aumentando o dinamismo e a precisão no processo de ensino-aprendizagem da PCV.

Seguindo essa premissa, Marchi e Silva (2016, p.468) concluem que: "Desta forma, torna-se indispensável que os cursos de formação continuada possibilitem a interação entre as dimensões pessoais e profissionais, de modo que a prática pedagógica seja reflexiva no sentido de fazer modificações pertinentes em busca de melhorar o desenvolvimento pessoal, profissional e do educando".

Com a pandemia da Covid-19, aumentaram as dificuldades em ensinar e aprender no sistema educacional e quando se trata dos alunos com deficiência visual, essa realidade é muito mais precária. Mesmo que as medidas tomadas perante esse período sejam de forma provisória, é de fundamental importância que sejam implementadas e garantidas ações educativas remotas e on-line pelas IE’s, em especial as públicas (Leite, Silva, Simões, Silva, \& Pereira, 2020).

E sabe-se que em lei é assegurado essa garantia de ações educativas em prol dos direitos à inclusão educacional nessa modalidade de ensino. Para que isso ocorra, se deve investir na formação continuada dos professores, ao passo que estes possam adaptar os instrumentos para todos os estudantes, com e sem deficiência e assim, sejam disponibilizados pelas IE's (Leite et al., 2020).

Apesar da escola analisada (cidade de Uberaba) na pesquisa de D. Pereira e Carvalho (2018) apresentar um aumento no número de matrículas de PDV e os Projetos Políticos Pedagógicos analisados possuírem ações inclusivas desenvolvidas, tais ações são colocadas em prática de forma isolada, pois não há indícios claros de diálogos entre as escolas que foram 
analisadas e os Departamentos de modo a resultar em um envolvimento maior nos projetos, podendo fortalecer as ações e participação das PDV;

Quanto aos livros didáticos tradicionais, há pouca produção de livros didáticos acessíveis, então é preciso que o poder público adote formas de incentivar a produção e distribuição de livros em formatos acessíveis a PDV, garantir o direito à leitura, à comunicação e à informação (Brasil, 2015; Bruno \& Nascimento, 2019).

E, ainda segundo a pesquisa de Bruno e Nascimento (2019), há uma necessidade de serem comprados materiais acessíveis a PDV, como livros, de modo a abastecer acervos e bibliotecas nos diversos níveis de modalidades de educação. Há uma necessidade de adoção de cláusula que impeça a aquisição de editoras que não possuam formatos acessíveis aos sujeitos cegos em seus acervos.

Tendo em vista que são muitos os caminhos a serem percorridos para a efetivação da inclusão da PDV no sistema educacional, D. Pereira e Carvalho (2018) destacam que não bastam os pequenos avanços que já foram feitos:

Mesmo com os avanços gradativos da sociedade, ainda há muito a contribuir na tentativa de valorizar e oportunizar a real participação desse grupo de pessoas que por longos anos ficou à margem da sociedade, lembrando que as mudanças não ocorrem rapidamente, uma vez que implicam questões políticas, científicas, pedagógicas, administrativas e financeiras (D. Pereira \& Carvalho, 2018, p.272).

Segundo a pesquisa de Gomes e Lins (2020) para que se alcance a inclusão educacional das PDV é preciso que haja uma bagagem de informação quanto ao tema por parte das pessoas que não têm deficiência. Foi pesquisado sobre a percepção de estudantes sem deficiência sobre os diversos conhecimentos relacionados ao tema e, se concluiu que tais estudantes conhecem as leis e as políticas públicas brasileiras voltadas à inclusão das PDV e algumas outras questões, como a falta de estrutura arquitetônica adequada. Porém, esse conhecimento sobre essas questões é superficial e não conhecem o Núcleo de Inclusão e Acessibilidade e suas atividades.

Gomes e Lins (2020) concluem que:

Para alcançarmos a inclusão social de maneira plena, é necessário o foco nas diferentes minorias, em políticas públicas e sociais específicas que vão além de apenas um discurso inclusivo, mas compreendendo as necessidades específicas de cada um desses grupos. Após conseguirmos o atendimento a essas singularidades, ao ponto de que a participação das minorias esteja presente no nosso cotidiano sem barreiras impeditivas, é possível pensar que a sociedade realmente é inclusiva. Retomando sempre a importância de incluir, invés de apenas integrar. Dessa maneira, é necessária a compreensão das relações sociais na dinâmica em que elas ocorrem, uma vez que as Leis e demais ações, como os planos, programas e projetos voltados para as pessoas com deficiência podem ser realizadas e pensadas também por pessoas que não possuem deficiência (Gomes \& Lins, 2020).

Veraszto, Camargo, Camargo, Simon e Miranda (2018) através de sua pesquisa com 47 alunos de diversas áreas das graduações de uma Universidade do Interior de São Paulo, notou uma ausência de disciplina específica para a questão da inclusão em si, pois a educação inclusiva é abordada em outras disciplinas, como as de metodologia e em algumas orientações para o estágio. Além disso, está claro que alunos pesquisados acreditam que os indivíduos e setores da sociedade devem estar cientes de seus papéis na educação, para que haja na prática inclusão das PDV.

\section{Considerações Finais}

A priori, com essa pesquisa de revisão bibliográfica, é possível destacar que as estratégias de inclusão da pessoa cega no sistema educacional ainda são precárias em termos de quantidade e, de fato, podem tornar os ambientes mais acessíveis para a PDV, mas longe de uma inclusão educacional propriamente dita. 
É preciso que haja debates constantes sobre as alternativas de promoção da acessibilidade para a pessoa com deficiência na educação e, por tanto, para que se caminhe para uma possível inclusão educacional futura. Deve-se haver uma busca contínua por subsídios de políticas de acessibilidade e educação inclusiva para além do embasamento no MEC, deve-se buscar então o desenvolvimento dessas políticas por parte de cada instituição de ensino, tendo em vista as séries de características próprias existentes nos espaços escolares de formação dos educandos com deficiência.

Apesar de haver estratégias que tornem o processo de ensino-aprendizagem mais acessível a PDV, há ainda muito esforço a ser feito para tornar o sistema educacional de fato inclusivo.

A educação inclusiva é discutida em cursos de graduação de forma superficial, onde é possível encontrar mais um pouco sobre esses conteúdos em momentos pontuais, como em aulas de estágio ou em apontamentos feitos para as práticas de ensino de disciplinas pedagógicas. E quando existe uma disciplina específica, acaba sendo optativa. Dessa forma, observamos que a educação inclusiva é tratada como um apêndice na formação inicial dos professores.

A formação continuada dos professores também se encontra escassa, então os docentes precisam buscar mais cursos preparatórios para lidarem com a realidade do aluno com deficiência visual, visto que é preciso cursos que os sensibilizem e estimulem a reflexão sobre a vivência do aluno cego nos espaços escolares, bem como o conhecimento de suas necessidades específicas, de modo a trabalhar em cima delas.

Há uma necessidade de os professores buscarem um debate e maior interação com os professores das salas de recurso, de modo a buscarem mais conhecimento e entendimento sobre a realidade da pessoa com deficiência e suas necessidades específicas, bem como a inserção de estratégias de ensino-aprendizagem.

Claramente, de acordo com as pesquisas, no sistema educacional, alunos cegos relatam que: se sentem excluídos; há uma necessidade dos professores se formarem melhor para melhor os ensinar; há uma necessidade de melhor adaptar os conteúdos como gráficos e conceitos de química e de se utilizar materiais táteis; se sentem incluídos, não sabem como e porquê; se sentem excluídos das disciplinas e escola como um todo, apesar de haver indícios de estratégias que tornem o ambiente mais acessível, como é o caso do piso podotátil.

Está longe de uma educação de fato inclusiva e o caminho ainda é bastante longo para que ela aconteça. Nesse contexto, o que fazemos em prol do processo da educação inclusiva, na realidade são estratégias que vão tornar o processo de ensino-aprendizagem cada vez mais acessível à pessoa com deficiência. Então, é preciso um investimento maior em políticas públicas voltadas para essa área.

Essa pesquisa serve como pressupostos básicos para a construção de várias pesquisas futuras sobre os assuntos que encerca essa temática e também, irá fazer com que os pesquisadores estejam cientes de aspectos que envolve a problemática em questão, podendo auxiliar na estrutura de suas pesquisas como aportes teóricos essenciais.

\section{Referências}

Azevedo, N. C. C. (2013). Da inclusão escolar do deficiente visual à educação para o sujeito. Revista Exitus, 3(2), $217-228$.

Brasil. Lei No 13.146, de 6 de julho. (2015). Institui a lei brasileira de inclusão da pessoa com deficiência (estatuto da pessoa com deficiência).

Brasil. (2008). Ministério da Saúde. Portaria no. 3.128, de 24 de dezembro de 2008. Define que as Redes Estaduais de Atenção à Pessoa com Deficiência Visual sejam compostas por ações na atenção básica e Serviços de Reabilitação Visual. Ministério da Saúde; 2008.

Brasil. (1994). Política Nacional de Educação Especial. MEC/SEESP.

Bruno, M. M. G., \& Nascimento, R. A. L. D. (2019). Política de Acessibilidade: o que dizem as pessoas com deficiência visual. Educação \& Realidade, 44.

Diniz, M. (2017). Inclusão de pessoas com deficiência e/ou necessidades específicas-Avanços e desafios. Autêntica. 
Research, Society and Development, v. 10, n. 10, e50101018553, 2021 (CC BY 4.0) | ISSN 2525-3409 | DOI: http://dx.doi.org/10.33448/rsd-v10i10.18553

Fortes, V. G. G. de F., \& Martins, L. de A. R. (2017). A formação continuada de professores do ensino médio integrado do ifrn: um dos caminhos para a inclusão de alunos com deficiência visual. Olhares: Revista Do Departamento De Educação Da Unifesp, 5(2), 31-53. https://doi.org/10.34024/olhares.2017.v5.749

Godoy, A. S. (1995). Introdução à pesquisa qualitativa e suas possibilidades. Revista de administração de empresas, 35(2), 57-63.

Gomes, C. S. C., \& Lins, J. L. D. S. G. (2020). A percepção da acessibilidade para pessoa com deficiência pelo estudante da Universidade Federal do PampaCampus Santana do Livramento. Research, Society and Development, 9(12), e29191211236-e29191211236.

IMPULSIONA. (2020). 5 Atividades dentro de casa para ensinar os filhos a respeitarem pessoas com deficiências. https://impulsiona.org.br/atividadespessoas-deficiencias

Lavorato, S. U., \& Mól, G. S. (2016). Percepção acerca da inclusão educacional na disciplina de química por alunos com deficiência visual. CIAIQ2016, 1.

Leite, L., Silva, M. C. R., Simões, T. M. S., Silva, A. C. S. \& Pereira, M. (2020). Impactos da Covid-19 na graduação da pessoa com deficiência visual. Revista Encantar-Educação, Cultura e Sociedade, 2, 01-14.

Lima, B. T. S. (2019). O ensino de química na percepção de alunos cegos: desenhando a inclusão no ensino médio. In: VI Congresso Nacional de Educação, 6., 2019, Fortaleza. Anais [...]. Fortaleza: Realize, 2019. p. 1-18.

Marchi, M. I., \& Silva, T. N. C. (2016). Formação continuada de professores: buscando melhorar e facilitar o ensino para deficientes visuais por meio de tecnologias assistivas. Revista Educação Especial, 29(55), 457-469.

Medeiros, L. R. (2020). Utilização de modelos táteis sustentáveis como alternativa no ensino de Química para alunos com deficiência visual. Discursos Interdisciplinares por uma Educação Transformadora, 35.

Miranda, A. A. B. (2004). História, deficiência e educação especial. Revista HISTEDBR On-line, 15, 1-7.

Moresi, E. (2003). Metodologia da pesquisa. Universidade Católica de Brasília, 108(24), 5.

Pereira, D., \& Carvalho, L. B. D. O. B. (2018). Políticas de fomento à leitura e ações para a participação da pessoa com deficiência visual em Uberaba-MG Revista Educação Especial, 31(61), 261-273.

Pereira, D. S. D. R., Tavares, H. S. D. E., \& Silva, F. M. (2021). Fatores que dificultam o trabalho do professor em uma sala de recursos multifuncionais. Revista Vox Metropolitana, 4, 99-112.

Plaisance, E. (2015). Da educação especial à educação inclusiva: esclarecendo as palavras para definir as práticas. Educação, 38(2), 231-238.

Ribas, J. (2017). Preconceito contra as pessoas com deficiência: as relações que travamos com o mundo. Cortez Editora.

Robalinho, B. C. S. D., \& Costa, C. S. (2019). Jogo Digital na inclusão de alunos com deficiência visual. Informática na educação: teoria \& prática, 22(1).

Selau, B., Damiani, M. F., \& Costas, F. A. T. (2017). < b> Estudantes cegos na educação superior: o que fazer com os possíveis obstáculos?. Acta Scientiarum. Education, 39(4), 431-440.

Stake, R. E. (2011). Pesquisa qualitativa: Como as coisas funcionam (K. Reis, Trad.).

Stake, R. E. (2016). Pesquisa qualitativa: estudando como as coisas funcionam. Penso Editora.

Urzedo, L. F. L., Jorge, C. A. M., \& Portela, C. P. (2020). Inclusão escolar com ênfase na deficiência visual. unifunec científica multidisciplinar, 9(11), 1-20.

Veraszto, E. V., Camargo, E. P. D., Camargo, J. T. F. D., Simon, F. O., \& Miranda, N. A. D. (2018). Evaluation of concepts regarding the construction of scientific knowledge by the congenitally blind: an approach using the Correspondence Analysis method. Ciência \& Educação (Bauru), 24(4), 837-857. 